\title{
A Global Comparison Between Brand-Name and Generic Drugs
}

\author{
Karan Chawla a, Taraneh Tofighi ${ }^{\mathrm{b}}$, Arnav Agarwal ${ }^{\mathrm{b}}$, Jason Thomas ${ }^{\mathrm{c}}$ and Tapas Mondal ${ }^{\mathrm{d}^{*}}$, \\ aHonours Biology (Physiology Specialization), Faculty of Science, McMaster University, 1280 Main Street West, Hamilton, ON, Canada, \\ L8S 4L8

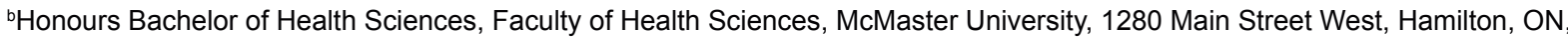 \\ Canada, L8S 4L8 \\ 'Pharmacy Services, Juravinski Cancer Center, 699 Concession Street, Hamilton, ON, Canada, L8V 5C2. \\ dDepartment of Pediatrics, McMaster Children's Hospital, 1200 Main Street West, Hamilton, ON, Canada, L8N 3Z5
}

\begin{abstract}
While the use of cheaper bioequivalent generic drugs over brand-name drugs has been widely discussed in literature, their market pricing and subsequent use is largely shaped by government policy-making as well as consumer and corporate decision-making. Analysis of literature shows that drug development and testing costs, degree of health care privatization, and pharmaceutical reimbursement all impact the profitability of brand-name drugs within and beyond their patent period. Furthermore, jurisdiction-specific government controls and policies influence the affordability and accessibility of both drug variants. This literature review focuses on: a) analyzing the policies and expenses associated with gaining approval for brand-name and generic drugs, and their subsequent influence on drug pricing; and b) comparing and contrasting government controls and policies between Canada, the United States, European nations, and developing countries.
\end{abstract}

Keywords: brand-name drugs, generic drugs, health policy, drug pricing, global comparison.

\section{INTRODUCTION}

There is much debate regarding the importance of promoting the use of cheaper generic alternatives over brand-name drugs. While generic drugs have been noted to be comparable to brand-name drugs in their ability to treat conditions, significant debate surrounding their bioavailability, or the concentration of the drug that reaches its site of action, has arisen. Many experts continue to believe that generic and brand-name drugs are bioequivalent and equally viable options for effective drug treatment, as assumed in this review. Generic drugs contain the same active ingredients present in brand-name drugs, but often differ in peripheral features that do not impact their bioavailability. ${ }^{1}$ The discussion of generic and brand-name drugs is relevant on a global scale, and relates to the affordability, and ultimately, the accessibility of pharmaceuticals for consumers worldwide.

In the United States (US), the Food and Drug Administration (FDA) is responsible for regulating the drug testing process in order to elicit potential health risks to consumers. ${ }^{2}$ While both brand-name and generic drug companies in the US must apply for FDA approval before being allowed to sell their drugs to the public, the former is required to undergo pre-clinical and costly threephase clinical testing in order to portray drug safety and efficacy. However, the latter is only required to undergo bioequivalence testing, or testing of pharmacokinetic properties, accounting for a significant
Submitted Date : 02-06-2014 Accepted Date : 04-09-2014

DOI: 10.5530/ijopp.7.3.6

Address for correspondence:

Dr. Tapas Mondal

Department of Pediatrics, McMaster Children's Hospital, 1200 Main Street West, Hamilton, ON, Canada, L8N 3 Z5

Phone: (905) 521-2100 x 75242

Fax: (905) 521-7914

E-mail: mondalt@mcmaster. ca

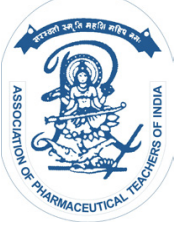

www.ijopp.org 
discrepancy in expenditures between brand-name and generic drugs and a subsequent inflation in the pricing of brand-name equivalents.

Discrepancies also exist in the drug policies of different countries, and this is the cause for the varying extent of generic and brand-name drug sales in different parts of the world. For example, the US has higher sales of generic drugs as compared to Canada and the UK owing to its privatized health care system. In contrast, governments in countries such as Canada and the UK cover a significant portion of pharmaceutical related costs, thereby reducing consumer incentive to purchase generic drugs at a lower price. However, in these countries, price restrictive policy making and co-payment practices continue to play a large role in the market forces that determine sales of generic drugs.

The purpose of this review is to investigate the factors that contribute to the high prices of brand-name drugs, as well as the lack of government policies promoting the use of generic drugs. The review is focused on addressing the following areas: a) analyzing the policies and expenses associated with gaining approval for brandname and generic drugs and their subsequent influence on drug pricing; and b) comparing and contrasting government controls and policies between North America, the UK, and other countries. This review is of significance to physicians, patients, pharmacists, and all those involved in policy-making, and it takes a global perspective in presenting topics of great importance to healthcare systems and providers all over the world.

\section{Part A: Costs of Generic and Brand-Name Drug Testing and Prices of Drugs in the Market}

\section{Cost associated with testing of the two drug types}

When a brand-name drug is in the process of being developed, it often cannot be compared to other drugs containing the same active ingredient, as no similar drugs exist in the market at the time of approval. ${ }^{3}$ For this reason, the drug must undergo extensive safety and efficacy testing in the form of preclinical and clinical trials. ${ }^{4}$ These trials are associated with considerable financial burden. ${ }^{5,6} \mathrm{It}$ is estimated by some sources that firms developing new drugs, on average, invest $\$ 802$ million into drug development and testing., ${ }^{5,7}$ However, studies that yielded these results were conducted on drugs which treat chronic diseases, and which must be analyzed over a long period of time in order to determine the long-term adverse effects. ${ }^{5}$ While this makes it possible that the estimated figure is an overestimate, other studies show this figure may in fact be an underestimate. ${ }^{8}$ Some studies have even revealed that firms developing novel drugs take on an estimated average financial burden of $\$ 868$ million during the development phase, with other evidence suggesting that the figure is likely to be closer to $\$ 1.3$ billion. ${ }^{8,9}$ Despite various estimates being proposed in the literature, it is for certain that the development of a novel drug involves costs which amount to hundreds of millions of dollars, resulting in a large drain on the financial resources of a firm.

This is not found to be the case for firms developing generic drugs. It has been estimated that the average cost of obtaining FDA approval to market generic drugs in the US in the early 1990 s was around $\$ 603,000 .{ }^{10}$ While this figure may have risen due to inflation since the early 1990s, it is still probable that the cost involved in the developmental process of generic drugs is currently lower than that of brand-name drugs by more than a hundredfold. This is a testament to the vast expenses involved in the implementation of clinical trials, a phase that is not a part of the process of gaining generic drug approval in the US, owing to the Waxman-Hatch Act that was passed in $1984 .{ }^{10}$ Similar laws have been passed in Canada, Japan, and Europe, allowing for significantly reduced developmental costs for generic drugs, in many parts of the world, compared to their brand-name counterparts. ${ }^{11}$

\section{Market prices of generic and brand-name drugs}

A very noticeable difference in prices between brandname and generic drugs exists in several countries around the world. ${ }^{12}$ Brand-name drugs have been shown to be priced 20 percent higher than generic drugs in the Netherlands, 30 percent higher in Germany, 50 percent higher in Canada, 50-90 percent higher in the US, and 80 percent higher in the UK. ${ }^{12}$ It has been estimated that generic drugs save Canadian consumers nearly $\$ 1$ billion annually. ${ }^{12}$ A potential reason for the price discrepancy between the two drug classes is the large difference in the costs associated with drug research and development. It is likely that firms who invest significant funds into developing novel drugs charge high prices for their products in order to recover these expenses. It is also likely that companies introducing novel drugs incur large marketing costs, due to the lack of knowledge among physicians regarding the ability of a newly introduced drug to treat a given disease. This further escalates the initial costs of these firms. ${ }^{13}$

While firms producing brand-name drugs must commit large sums of money into development and marketing costs, their investments yield significant revenues during, as well as after, the patent period of the drug. This has been revealed by several studies, one of which examined the sales of Fosamax, a drug that yielded sales of $\$ 3$ billion in the year 2007 alone. ${ }^{14}$ While sales of this drug dropped after the introduction of generic alternatives to the drug in the February of the following year, sales 
still amounted to $\$ 1.5$ billion in $2008 .{ }^{14}$ Hence, Fosamax produced an annual revenue that exceeded the average total amount of money spent on the research and development of a drug despite the expenses it incurred. ${ }^{14}$

It is clear that firms are able to continue making a large, albeit reduced, number of sales even after the entry of generic drugs into the market. This was supported by data obtained from a survey conducted across all 50 states of the US, in which 2,500 commercially-insured beneficiaries participated. ${ }^{15}$ Analysis of the results showed that majority of the participants believe generic drugs are less costly, and do not believe that generic drugs cause worse side effects compared to brand-name drugs. ${ }^{15}$ Additionally, they also did not believe that generic drugs were less effective compared to brand-name drugs ${ }^{15}$. Despite this, the results of the survey indicated that only 37 percent of the participants would rather take a generic drug over a brand-name drug. ${ }^{15}$ Assuming this survey is representative of the composite US population, if given the choice, 67 percent of Americans would consume a brand-name drug over its generic alternative. ${ }^{15}$ This higher demand for brand-name drugs may be responsible for the continued presence of elevated prices, even after the introduction of generic drugs into the market. ${ }^{16}$

As discussed, people residing in the US and other 'first world' countries pay high prices for brand-name drugs. ${ }^{5}$ However, these medications would not be affordable for those living in nations with annual per capita incomes of under $\$ 1,000 . .^{5}$ As a result, drug companies are encouraged by world health authorities to sell their drugs at lower prices in these nations. ${ }^{5}$ Drugs may be as much as five times cheaper in developing countries as compared to market prices in 'first world' nations. ${ }^{5}$ While this is a positive step in making drugs accessible to those who are unable to afford them, this substantial cross-national difference in drug prices involves several drawbacks as well. ${ }^{5}$ Firstly, the price difference allows for the export of drugs from low-price jurisdictions to higher price ones, thereby potentially undermining the purpose of lowering prices in developing countries. ${ }^{5}$ Secondly, the large cross-national difference in prices results in unfair treatment of those living in 'first world' nations, who must pay high prices for brand-name drugs regardless of their financial status. ${ }^{5}$ The elevated prices of brand-name drugs are a major source of debate today. Governing bodies around the world must introduce consistent policies which will put to rest all controversy surrounding the topic of brandname drug prices.

Part B: Influence of Government Policy in Market

\section{Pricing and Consumption of Generic Drugs - International Scope}

\section{Canada}

Within the past few decades, several studies have suggested that Canadian generic drugs are priced above the international standard, limiting the accessibility and consumption of these drugs. ${ }^{17}$ In fact, a Canadian and U.S. comparison study published in 2002 reported that an astounding 78 percent of top selling generic drugs were priced higher in Canada. ${ }^{18}$ From its inception, the Canadian public health care system has been decentralized, with health policy and care falling within the jurisdiction of the provinces. As a direct result, each province has unique policies pertaining to the distribution and public reimbursement of generic drugs. ${ }^{19,20}$ Statistical data reveals asymmetry and inconsistency in the pricing of generic drugs in Quebec, Ontario, and the West Coast as a result of varying government policies implemented in each province. ${ }^{21}$

Although each Canadian province strives to encourage the sale of generic drugs in order to control drug plan expenditures, the limitations of the provincial policies hinder natural market forces from influencing generic drug pricing and consumption. In 1993, the Ontario government introduced the 75/90 rule, which mandated that pharmacies could only be reimbursed for dispensing primary generic drugs priced at up to 75 percent of the related brand name drug, and subsequent generics priced at no more than 90 percent of the primary generic drug. ${ }^{21,22}$ While this price-fixing policy was implemented to place a ceiling on generic drug costs and minimize health care spending, it also acted to inflate generic drug prices by removing incentives for competition between retail pharmacies. ${ }^{16}$ Throughout the years, both public and corporate influences led to modifications of the policy, first to the $60 / 90$ rule and later to the $70 / 90$ rule, with subsequent amendments in 2007 and 2010 further lowering the maximum price of the first generic drug relative to the brand name. ${ }^{23,24}$ Although these amendments are progressive movements towards lowering the cost of generic drugs in Canada, it has been suggested that the government would benefit from lifting price ceilings altogether and allowing market forces to determine the pricing of generic drugs. The province of Quebec implements policies that resemble generic drug policies in Ontario, with price floors that inflate generic drug prices and ultimately lower sales. ${ }^{21}$

The remaining provinces uphold similar policies to those present in Ontario and Quebec, although British Columbia implements reference based pricing of generic drugs to encourage competition. ${ }^{23}$ By offering full reimbursement to pharmacies offering the lowest- 
cost generic drugs as opposed to the partial benefits associated with higher priced generic drugs, the province encourages lower prices of generic drugs. As a result, British Columbia boasts the highest proportion of generic drug prescriptions in the country. However, as Ontario accounts for nearly 45 percent of drug expenditures within the country, current Ontario pharmaceutical policies significantly influence and shape the entire Canadian generic drug market. ${ }^{25}$

Another mechanism underlying costly generic drugs in Ontario, and other Canadian jurisdictions, relates to the 'co-payment' structure of the national health care system in relation to coverage of prescription drugs. The public sector covered 46 percent of prescription drug costs in 2007, with publically covered recipients paying a small co-payment. This co-payment is unrelated to the total prescription cost, hence there is little incentive for consumers to purchase lower cost generic drugs. Such a policy restricts supply-demand price adjustments of generic drugs for consumers covered by the public sector, and it is possible that a percentage based copayment system would allow for natural market adjustments to occur based on the price of pharmaceuticals. ${ }^{26}$

\section{United States}

A combination of natural market forces, increased consumer decision-making, and progressive policy reforms have resulted in a more significant tendency towards generic drug prescription and consumption in the US. A comparative study between the US and Canada, conducted in 2008, highlights the disparity in generic drug pricing and associated expenditures between the countries, reporting increased price savings of 47 percent in the former. ${ }^{27}$ This difference can be attributed to the direct competition present in the US market, where the government does not place regulations on the pricing of generic drugs.

Policy changes have also been fundamental to the progression of generic drug substitution over time. In 1984, the Waxman-Hatch Act was implemented with the primary goal of encouraging market entry of generic drugs after patent expiration of the corresponding brand-name drugs. ${ }^{28}$ This act resulted in a reform of generic drug sales, as prior to the establishment of the Waxman-Hatch Act, anti-substitution laws of the 1950s and 1960s banned pharmacists from substituting the less expensive generic drugs for the brand-name alternative. However, with the repeal of these laws and the introduction of the Waxman-Hatch Act, generic drugs were made available to the public with prices driven down by consumer market forces. ${ }^{28,29}$ Although there were several contributing factors, the Waxman-Hatch Act is attributed to the progressive shift in the increased prescription of generic drugs, from 10 percent in the early 1980s to approximately 40 percent in the 1990s. ${ }^{29}$ It is important to examine the Waxman-Hatch Act from numerous angles, including the effects of generic drug sales on drug innovations. While the introduction of the Waxman-Hatch Act has been advantageous in increasing generic drug sales, its introduction has also caused brand-name pharmaceuticals with expired patents to lose over 50 percent in sales during the first few months of generic drug competition. ${ }^{28}$ This prevalence of generic drugs may discourage pharmaceutical innovations and developments in the future, possibly requiring the introduction of policies that extend the length of patent periods in order to encourage brand-name companies to continue producing new and innovative drugs. ${ }^{28-30}$ Despite these drawbacks, the significantly lower prices of generic drugs in the US warrant consideration of the effects of government policy on pricing, and the benefits of fostering competition within the generic drug market.

\section{Europe}

In order to gain insight on the pharmaceutical drug industry in Europe, it is important to consider the national policies enacted by European Union member nations. As in the decentralized health care system within Canada, there are varying degrees of asymmetry in the pricing of generic drugs within Europe, with the literature suggesting that the pricing of generic drugs is significantly lower in Scandinavian countries compared to their pricing in countries like France, Germany, and the United Kingdom. ${ }^{31}$ These cross-national differences indicate that national policy making plays a noticeable role in determining the market availability and pricing of generic drugs.

An analysis conducted in 2011 by the European Generic Medicines Association revealed that approximately 80 percent of European nations enacted generic price fixing policies similar to those in the Canadian model, whereas 20 percent limited government interference by enabling free-market price adjustments similar to the US model. ${ }^{32}$ In order to fully understand the implications of such policy making, it is important to note that the purchase of pharmaceutical drugs is fully covered by the public sector in the majority of European countries, thus placing reimbursement policies at the forefront of discussion. Similar to the previous discussions centered on the differences between the US and Canadian policy making models, the literature has revealed that generic drug pricing is lower and market availability is higher in nations that abandon percentage reimbursement in favour of free-market competition. ${ }^{32,33}$ These studies take basis in information revealing that fixed prices tend 
to create a monopoly by limiting the number of generic drugs that enter the market, thus limiting consumer choice and price competition. It should be noted that of the European countries that enact policies controlling the pricing of generic drugs, 37 percent outline the percentage pricing of generic drugs in relation to the corresponding brand-name drug, while 31 percent stipulate a maximum price for generic drugs, with the remaining 16 percent fixing prices in accordance to the average data on the pricing of generic drugs in a sample of European countries. ${ }^{32}$ In nations that adopt fixed price policies, there are still varying forms of competition, namely in the case of pharmacists receiving discounts based on sale of generic drugs. In many European countries, generic drug companies may compete by providing discounts to pharmacists and wholesalers to carry their drugs, although costs are not lowered to the same extent as free market competition. ${ }^{34}$

Reference pricing policies emerging in European countries, including Belgium, Bulgaria, Czech Republic, Denmark, Finland, France and the Netherlands, provide a means to contain expenditures within the insured public sector without inhibiting direct price competition. The policies encompass the concept of 'co-payment', in which a drug is only reimbursed to consumers if it is at or below the determined reference price for a group of equivalent medicines, with consumers making up the difference. ${ }^{35}$ Although there is a pressure on companies to adhere to certain reference prices, there is no 'price ceiling' or maximum, ensuring that competitive forces control the market while not directly limiting company pricing. ${ }^{35}$

\section{Developing Countries}

With the rise of diseases and the particular surge in HIV/AIDS in several developing countries, the need for accessible and cheap generic drugs is apparent. The emergence of trade policies between developed and developing nations and existing patent rights continue to play a large role in both the pricing and availability of developing drugs. Since the introduction of a policy in India, in 1970, which eliminated drug patents, India has been an international contributor of the generic drugs used to treat HIV/AIDS, alongside various generic drugs used to treat cancer and various cardiovascular diseases. ${ }^{36}$ However, developed nations continue to influence policy making in developing countries, as noted in the negotiations between India and the World Trade Organization relating to the implementation of patent protected drugs. The continual influence of generic drug policies in developed countries plays a significant role in shaping both the development and pricing of generic drugs in developing countries, where the majority of the population is in need of inexpensive medication. ${ }^{37}$

\section{DISCUSSION}

This review of the literature on brand-name and generic drugs produced several primary findings relevant to profitability, consumer demand and accessibility, and government influences on generic drug markets globally. The development of brand-name drugs was found to be significantly more expensive relative to generic drug development, contributing in part to the substantial difference in prices between the two drug types. Brand-name drugs were reported to make major profits during their patent periods but also continue to reap significant financial benefits following this period. This largely owes to the fact that consumers typically purchase brand-name drugs despite their awareness of the presence of generic drugs on the market. Furthermore, policy-making was found to have a significant influence on the accessibility of generic drugs, as is clearly evident in a comparison of the extent of generic drug use between Canada, the US, and various European nations. A global spectrum in the influence of government policy and price control was also observed, taking various forms including percentage pricing in relation to brandname drugs, maximum pricing, price-fixing, or an uninfluenced free-market system.

This review considered numerous sources of literature in providing an extensive global overview of drug policy and market trends. Identified literature often emphasized the policies and practices limited to a specific jurisdiction. This paper introduces the factors influencing expenditures and prices of generic and brand-name drugs from a producer perspective, and takes a multinational and multi-perspective approach to comparing the role of government, policy, and consumer and pharmacy incentives in determining the degree of generic drug use relative to brand-name drugs. However, the unsystematic nature of this review limits the comprehensiveness of the paper and its representativeness of all available literature on the topic. Moreover, its emphasis on developed countries restricts the applicability of several of its findings to countries with similar demographics, consumer markets, and governmental organizations. Finally, this analysis assumes the bioequivalence of the two drug types, which has been an area of controversy and warrants further examination.

\section{CONCLUSION}

In conclusion, this review identified a relationship between brand-name drug development expenses and subsequent elevated drug prices. Despite these expendi- 
tures and the limits placed on brand-name drug patents, brand-name drugs continue to benefit from significant profits beyond their patent period. Government controls and drug policies vary in nature globally and play a major role in consumer decision-making and the degree of generic drug success, taking various forms across different jurisdictions. Future directions include an exploration of government policies and the proportion of generic drug use in developing countries, as well as a validation of the assumption that generic and brandname drugs are in fact bioequivalent.

\section{ACKNOWLEDGEMENTS}

We would like to thank Shaibaal Roy for assisting with revision of the manuscript.

\section{FINANCIAL DISCLOSURES}

None.

\section{REFERENCES}

1. Kesselheim AS, Misono AS, Lee JL, et al. Clinical equivalence of generic and brand-name drugs used in cardiovascular disease. JAMA. 2008; 300(21): 2514-26.

2. Stafford RS. Regulating off-label drug use-rethinking the role of the FDA. New England Journal of Medicine. 2008; 358(14): 1427-9.

3. Szejtli J. Cyclodextrin complexed generic drugs are generally not bioequivalent with the reference products: therefore the increase in number of marketed drug/cyclodextrin formulations is so slow. Journal of Inclusion Phenomena and Macrocyclic Chemistry. 2005; 52(1-2): 1-11.

4. Scott Morton FM. Barriers to entry, brand advertising, and generic entry in the US pharmaceutical industry. International Journal of Industrial Organization. 2000; 18(7): 1085-104.

5. Scherer FM. The pharmaceutical industry-Prices and progress. New England Journal of Medicine. 2004; 351(Issue missing) : 927-32.

6. Teff $\mathrm{H}$. Drug Approval in England and the United States. The American Journal of Comparative Law.1985; 33(4): 567-610.

7. DiMasi JA, Hansen RW, Grabowski, HG. The price of innovation: new estimates of drug development costs. Journal of health economics. 2003; 22(2): 151-85.

8. Adams CP, Brantner VV. Estimating the cost of new drug development: is it really $\$ 802$ million? Health Affairs. 2006; 25(2): 420-8.

9. Roy ASA. (2012). Project FDA Report: Stifling New Cures: The True Cost of Lengthy Clinical Drug Trials [Internet]. Retrieved by http://www.manhattaninstitute.org/html/fda_05. htm

10. Reiffen D, Ward MR. Generic drug industry dynamics. Review of Economics and Statistics. 2005; 87(1): 37-49.

11. Karalis V, Macheras P. Current regulatory approaches of bioequivalence testing. Expert Opinion on Drug Metabolism \& Toxicology. 2012; 8(8): 92942.

12. King DR, Kanavos P. Encouraging the use of generic medicines: implications for transition economies. Croatian Medical Journal. 2002; 43(4): 462-9.

13. Olson MK. Are novel drugs more risky for patients than less novel drugs? Journal of Health Economics. 2004; 23(6): 1135-58.
14. Higgins MJ, Graham SJ. Balancing innovation and access: patent challenges tip the scales. Science.2009; 326(5951): 370-1.

15. Shrank WH, Cox ER, Fischer MA, et al. Patients' perceptions of generic medications. Health Affairs. 2009; 28(2): 546-56.

16. Lexchin J. The effect of generic competition on the price of brand-name drugs. Health Policy. 2004; 68(1): 47-54

17. Rovere M, Skinner BJ. Ontario's generic drug pricing debacle. In Fraser Forum; 2010. p. 16-8.

18. Palmer D'Angelo Consulting Inc. (2002) Generic Drug Prices: A Canada US Comparison. Retrieved from Palmer D'Angelo Consulting Inc. Marketing Access website: http://www.pdci.ca/pdf/Generic\%20Pricing $\% 20$ Study $\% 20$ Final\%20Report.pdf

19. Health Canada. (2012). Canada's Health Care System [Internet]. Retrieved from http://www.hc-sc.gc.ca/hcs-sss/pubs/system-regime/2011-hcs-sss/ index-eng.php

20. Anis $\mathrm{AH}$. Substitution laws, insurance coverage, and generic drug use. Medical Care. 1994; volume and issue missing ? 240-56.

21. Canadian Treatment Action Council. (2007). Generic Drugs in Canada: A Policy Paper. Retrieved from Canadian Treatment Action Council website: http://www.ctac.ca/uploads/Position\%20Papers/2007\%20EN_PP\%20 Generic_Drugs_in_Canada_April_2007_FINAL.pdf

22. Rovere M. Reforming Ontario's public drug plan. In Fraser Forum; 2012. pp. 25-7.

23. Gorecki PK. A comparison of two drug reimbursement pricing models: BC Pharmacare and the Ontario Drug Benefit Programme. Canadian Journal of Economics. 1993.

24. Anis $\mathrm{AH}$, Guh DP, Woolcott J. Lowering generic drug prices: less regulation equals more competition. Medical Care. 2003; 41(1): 135-41.

25. Currie GR, Nielson NL. Models for Funding Prescription Drug Programs. Institute of Health Economics; 1999.

26. Hurley J, Johnson NA. The effects of co-payments within drug reimbursement programs. Canadian Public Policy/Analyse de Politiques. 1991; 473-89.

27. Gooi M, Bell CM. Differences in generic drug prices between the US and Canada. Applied Health Economics and Health Policy. 2008; 6(1): 19-26.

28. Grabowski H, Vernon J. Longer patents for increased generic competition in the US. PharmacoEconomics. 1996; 10(2): 110-23.

29. Frank RG, Salkever DS. Generic entry and the pricing of pharmaceuticals. Journal of Economics \& Management Strategy. 1997; 6(1): 75-90.

30. Giaccotto C, Santerre RE, Vernon JA. Drug Prices and Research and Development Investment Behavior in the Pharmaceutical Industry. Journal of Law and Economics. 2005; 48(1): 195-214.

31. Simoens S. A review of generic medicine pricing in Europe. GaBI Journal. 2012; 1(1): 8-12.

32. European Generic Medicines Association. 2011 market review: the European generic medicines markets. Brussels: European Generic Medicines Association; 2011.

33. Brekke KR, Grasdal AL, Holmås TH. Regulation and pricing of pharmaceuticals: Reference pricing or price cap regulation? European Economic Review. 2009; 53(2): 170-85.

34. Simoens S. Generic medicine pricing in Europe: current issues and future perspective. Journal of Medical Economics. 2008; 11(1): 171-5.

35. Dylst P, Vulto A, Simoens S. Reference pricing systems in Europe: characteristics and consequences. Generics and Biosimilars Initiative Journal. 2012; 1(3-4): 127-31.

36. Love J. The production of generic drugs in India. BMJ. 2011.342.

37. Correa C. Trade related aspects of intellectual property rights: a commentary on the TRIPS agreement. OUP Catalogue; 2007. The citation I have for this is: Correa CM. Trade related aspects of intellectual property rights: A commentary on the TRIPS Agreement. Oxford: Oxford University Press; 2007. p. 44-6. http://ukcatalogue.oup.com/product/9780199271283.do 